\title{
BRAIN COMPUTED TOMOGRAPHIC FINDINGS OF STROKE PATIENTS IN MAIDUGURI, NORTH-EASTERN NIGERIA
}

\author{
${ }^{1}$ Umar UH, ${ }^{2}$ Yunusa DM,,${ }^{1}$ Farate $\mathrm{A},{ }^{1}$ Ahmadu MS, ${ }^{3}$ Umar UA, ${ }^{3}$ Ali AM \\ ${ }^{1}$ Department of Radiology, University of Maiduguri Teaching Hospital, Maiduguri, Nigeria \\ ${ }^{2}$ Department of Radiology, Federal Medical Centre, Yola, Nigeria \\ ${ }^{3}$ Department of Radiology, Federal Neuro-psychiatric Hospital, Maiduguri, Nigeria
}

Correspondence and reprint request to: Dr Umar Hassan Umar, Department of Radiology, University of Maiduguri Teaching Hospital, PMB 1414, Maiduguri, Nigeria,

Email: umarhub@gmail.com Phone no.: +2348037614515,

\begin{abstract}
Background: Stroke is a major neurological condition with high disability and mortality rates in developing countries including Nigeria. Computed tomography (CT) scan is an important imaging modality in confirming the diagnosis of stroke, classifying stroke subtypes and ruling out stroke mimics. Objectives: To determine the CT findings of patients with stroke in Maiduguri, North-eastern Nigeria. Methodology: A retrospective hospital-based study conducted at the Department of Radiology, Federal Neuro-psychiatric Hospital, Maiduguri, North-eastern Nigeria over four-year period from January 2015 to December 2018. All patients were clinically diagnosed with stroke and referred to the department for a brain CT scan. The request forms and $\mathrm{CT}$ reports were retrieved from the Archive and analysed. All patients were examined with a 16-slice General Electric CT scanner. Data were analysed using SPSS statistical software version 23. Results: There were 138 patients and out of which, $83(60 \%)$ were males and $55(40 \%)$ females with a male to female ratio of $1.5: 1$. The mean age was $51.6 \pm 16.6$ years with an age range of 5-85 years and the majority of the patients were middle-aged group. The CT findings showed 88 (64\%) were confirmed stroke cases and the remaining 50 (36\%) were misdiagnoses of stroke, with normal finding in $23 \%$ and stroke mimics in the remaining $13 \%$. Brain infarction was the most common stroke subtype accounting for $64 \%$ of the patients, followed by intracerebral haemorrhage of $33 \%$ and $3 \%$ had subarachnoid haemorrhage. The left cerebral hemisphere was the most commonly involved. Cerebral atrophy and brain tumours were the two most common stroke mimics in this study and they were mostly seen in females than males. Conclusion: In this study, the accuracy rate of clinical diagnosis of stroke was low. Therefore, CT scan is the 'gold standard' in the diagnosis of stroke and it is strongly recommended in the management of all stroke patients.
\end{abstract}

Key words: Computed Tomography, Maiduguri, Stroke, Stroke Mimic, Stroke Side, Stroke Subtype

\section{INTRODUCTION}

Stroke, also known as cerebrovascular disease (CVD), is the second leading cause of death after ischaemic heart disease and the third leading cause of disability, Worldwide. ${ }^{1,2}$ It is

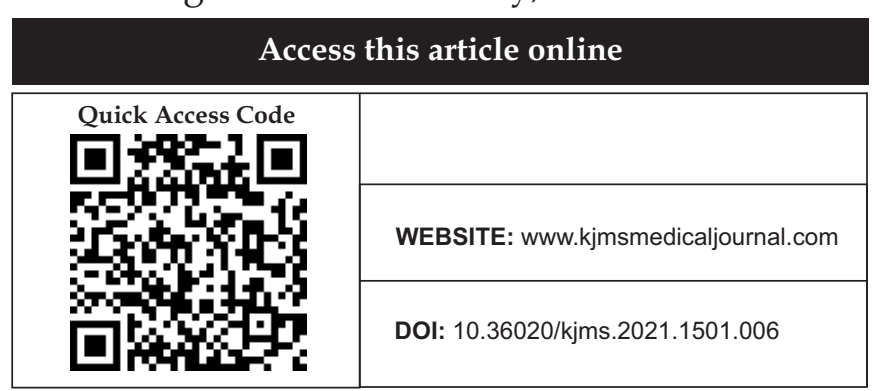

mainly characterized as a focal neurological deficit of the central nervous system (CNS) of vascular cause, including brain infarction (BI), intracerebral haemorrhage (ICH) and subarachnoid haemorrhage $(\mathrm{SAH}) .^{3}$ In contrast to the declining stroke rates in most developed countries, the incidence of stroke in Africa including Nigeria has risen over the last two decades and about $86 \%$ of all stroke deaths around the world are contributed by low- and middle-income countries in Africa and other developing countries. ${ }^{4}$ From the global burden of diseases, stroke incidence appears to be 
increasing in Africa and the proportion of haemorrhagic stroke ranges from $29-57 \%$, in comparison with $16-20 \%$ found in developed countries. ${ }^{4}$ However, BI accounts for the majority of cases (about $80 \%$ ) globally. ${ }^{5}$ In several studies from the West African sub-region, stroke is the leading cause of adult neurological admissions, constituting up to $65 \%$. ${ }^{4}$ The crude prevalence rate of stroke in Nigeria was 1.14/1,000 population ${ }^{6}$ and it was higher in males than females. ${ }^{2}$ Previous community-based study in South-western Nigeria showed a trend of increasing prevalence with advancing age. ${ }^{6}$

Current guidelines for the management of acute stroke recommend a course of treatment based on the diagnosis of subtype of stroke (ischaemic or haemorrhagic) using neuro-imaging with computed tomography (CT) or magnetic resonance imaging (MRI). In some cities and villages in Nigeria, CT and MRI are not readily available or affordable, thus making clinicians make difficult clinical decisions, such as deciding which patient will benefit from anticoagulant therapy and to what level to control patients' blood pressure. ${ }^{1,7}$ Computed tomography is relatively available and affordable than magnetic resonance imaging (MRI) and usually able to exclude stroke mimics like brain tumours, subdural haemorrhage (SDH) and abscess. ${ }^{3}$ The duration of CT scanning is less compare to MRI, which should be considered in critically ill patients and then, brain CT scan is the first imaging modality employ in evaluating of patients with acute stroke, especially in the exclusion of haemorrhagic subtype. ${ }^{7,8}$

Previous studies in Maiduguri, North-eastern Nigeria on stroke in which validation of Siriraj stroke score and comparison of hospital stroke scores with $\mathrm{CT}$ scan findings were reviewed but confirmation of stroke mimics and differentiating $\mathrm{ICH}$ and $\mathrm{SAH}$ were not highlighted in these studies. ${ }^{7,9}$ Salawu et $a l^{8}$ in their study reported low sensitivity, specificity, positive predictive value and accuracy rate of clinical stroke scores in diagnosing stroke and confirming its types and they concluded that cross-sectional imaging is irreplaceable in the clinical management of patients with stroke. ${ }^{8}$ Watila et $a l^{10}$ in a study in Maiduguri reported that only a few $(21 \%)$ of all stroke patients had neuroimaging (CT or MRI), where WHO criteria and Siriraj stroke score were mostly used for the diagnosis and differentiating stroke subtypes. ${ }^{10}$ Similarly, in another study conducted in Kano, North-western Nigeria, only $39 \%$ of stroke patients had neuroimaging done. ${ }^{11}$ Almost similar findings were reported in other studies in North-western, South-western ${ }^{13}$ and South-eastern ${ }^{14}$ Nigeria. A similar trend was documented in other subSaharan African countries including Ghana, ${ }^{15}$ Senega ${ }^{16}$ and Tanzania. ${ }^{17}$ Some of the reasons for not doing neuroimaging in these studies were; nonavailability, poverty and illiteracy. However, a study in North-Central Nigeria by Alkali et al showed that most of the stroke patients (97\%) had neuroimaging done.

Previous studies revealed that 2.5 to $34 \%$ of patients were misdiagnosed as having stroke based on clinical assessment and after performing brain CT scans, these patients either had normal neuroimaging findings or had stroke mimics., ${ }^{5,18-25}$ However, Ogun et $a l^{26}$ in South-western Nigeria reported as high as $43 \%$ of clinical misdiagnosis of stroke in their study. The accuracy rate of the clinical diagnosis of stroke was usually less than $85 \%$ (range $57-90 \%$ ) as reported in many studies in Nigeria ${ }^{5,8,20-26}$ and an almost similar finding was also reported in Pakistan, Asia. ${ }^{27}$

The BI is the most common subtype of stroke in most studies (ranging from 54\% to $85 \%$ ) from Northern ${ }^{7-9,18,26,28}$ and Southern ${ }^{5,14,20-25}$ Nigeria, and other Sub-Saharan African countries ${ }^{15,16,29}$ and also some Asian countries. ${ }^{27,30-32}$ The left cerebral hemisphere was the most common site affected in stroke patients in previous studies. ${ }^{5,21}$ Most studies also showed that in all stroke subtypes, they were more common in males than females. ${ }^{5,21,24,28,31,33}$ Brain atrophy and tumours were the two most common stroke mimics reported by previous researchers in Nigeria. ${ }^{1921,25,26}$ A study on stroke patients was reported from Gombe, North-eastern Nigeria but the parameters such as stroke side and mimics were not highlighted. ${ }^{28}$

To the best of our knowledge, there is a paucity of literature in Maiduguri and entire North-eastern Nigeria on brain CT findings in stroke, this prompted this study. This study aimed to determine the CT findings of patients with stroke in Maiduguri, North-eastern Nigeria. 


\section{MATERIALS AND METHOD}

This was a four-year retrospective study of clinically diagnosed stroke patients that were referred for brain CT at the Radiology department of Federal Neuro-psychiatric Hospital, Maiduguri, North-eastern Nigeria from January 2015 to December 2018. The patients were mainly referred from Medical wards and Accident and Emergency units of the University of Maiduguri Teaching Hospital and State Specialist Hospital, Maiduguri, Nigeria and the remaining were from peripheral hospitals in Borno state and neighbouring Yobe state. All examinations were performed using a 16slice CT scanner (General Electric, BrightSpeed ${ }^{\circledR}$ Waukesha, WI, USA). The request forms and CT reports were retrieved from the Archive and were reviewed. All patients (or care-givers of unconscious patients) gave informed consent before CT scan examination and ethical guidelines on medical research were followed. Relevant clinical information such as the age, sex, and clinical features and clinical diagnosis were obtained from the patients' request forms and the CT findings were obtained from CT scan reports. However, some patients were excluded from the study and the exclusion criteria include: those with recurrent stroke and those with stroke lasting for more than 15 days because of the problem of differentiating infarction and haemorrhage at that stage. ${ }^{8}$

The CT findings were categorized into: stroke, stroke mimic and normal. The stroke subtypes include $\mathrm{BI}, \mathrm{ICH}$ and $\mathrm{SAH}$ and the stroke sides include left hemisphere, right hemisphere and bilateral. The stroke mimics (clinically misdiagnosed as stroke) include: intracranial (IC) tumours, subdural haemorrhage, IC infection, IC arteriovenous malformation (AVM) and cerebral atrophy. All CT scan examinations were reported by two experienced consultant Radiologists. Brain infarction is typically seen as a hypodense area in the cerebral hemisphere on the CT image (Figure 1), while $\mathrm{ICH}$ is seen as a hyperdense area in the cerebral hemisphere (Figure 2).

Data were processed and analysed using SPSS version 23 statistical software. Descriptive data were presented in mean ( \pm standard deviation), range, ratio and percentages. Relationships between variables were evaluated using chi-square, Fisher's exact and Student t-tests. A confidence interval of $95 \%$ was used and a p-value of $<0.05$ was considered statistically significant.

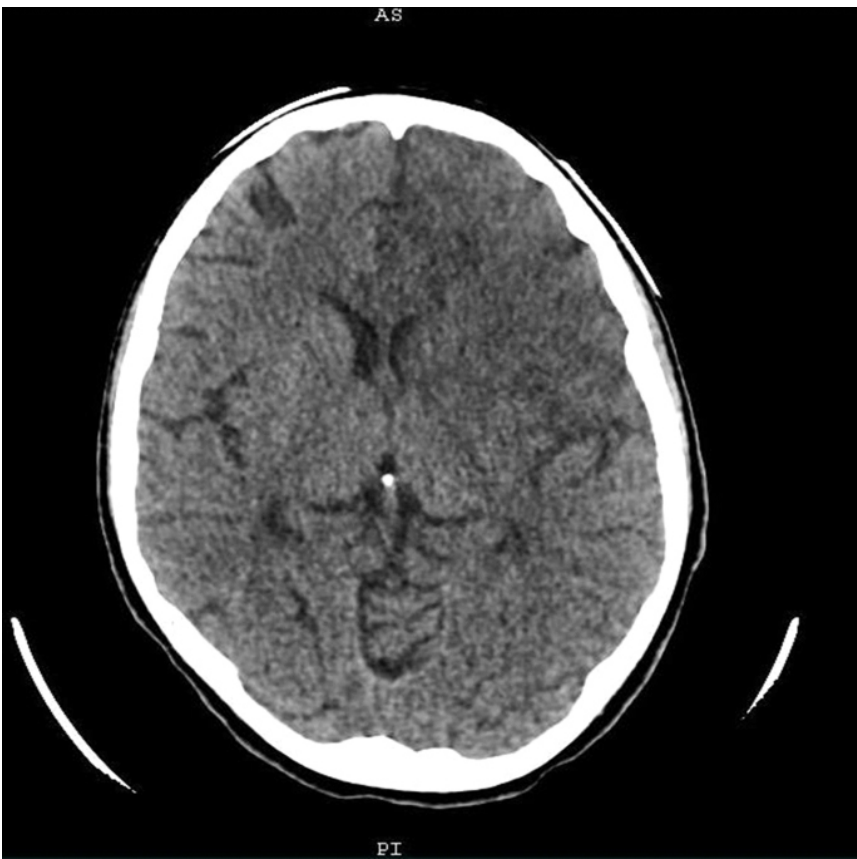

Figure 1: Axial non-contrast enhanced computed tomographic image showing hypodense area with loss of grey-white matter differentiation in the left fronto-parietal region and compression of adjacent frontal horn of left lateral ventricle representing acute cerebral infarction.

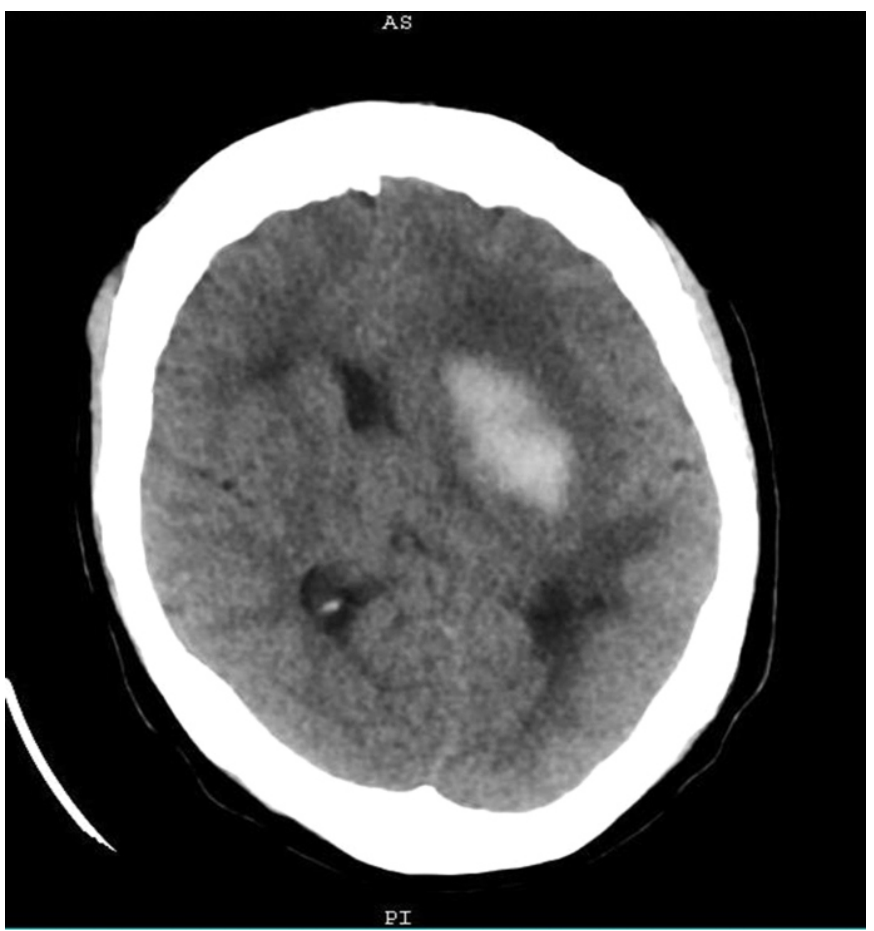

Figure 2: Axial non-contrast enhanced computed tomographic image showing a hyperdense area with surrounding area of hypodensity due to perilesional oedema at the region of left lenti-form nucleus and internal capsule with ipsilateral mass effect as evidenced by shifting of midline to the right and compression of left lateral ventricle representing acute intracerebral haemorrhage. 


\section{RESULTS}

There were 138 stroke patients reviewed during the four-year study period. Of these, $83(60 \%)$ were males and $55(40 \%)$ were females with a male to female ratio of 1.5:1. The mean age was $51.6( \pm 16.6)$ years with an age range of 5 to 85 years and almost half of the patients were in the age group of 41-60 years as shown in Table 1.

Table 2 shows the CT findings of the clinically diagnosed stroke patients, of which only 88 (64\%) of the patients had confirmation of stroke on CT scan.

The remaining $50(36 \%)$ patients were clinical misdiagnoses of stroke (either stroke mimic or normal). It also showed males were more affected than females in the stroke patients which were confirmed on CT scan. However, there was no statistically significant difference in $\mathrm{CT}$ findings among the two sexes $(\mathrm{p}=0.30)$. Of the 88 patients with confirmed CVD, 56 (64\%) had BI while the remaining $32(36 \%)$ had a haemorrhagic stroke (including ICH and SAH) as shown in Table 3 and
$55(62 \%)$ patients were males and the remaining 33 $(38 \%)$ were females. Also, there were more males than females in all stroke subtypes. However, their relationship was not statistically significant $(p=0.68)$. Only 4 patients $(5 \%)$ of the confirmed stroke patients were of paediatric age ( $<18$ years), in which, there were 3 cases of $\mathrm{BI}$ and a case of $\mathrm{ICH}$. Thirteen $(15 \%)$ of the patients were young adults (18-40 years of age) with 7 cases of BI, 4 cases of ICH and 2 cases of SAH.

Table 4 shows that the left cerebral hemisphere was the most commonly involved side, accounting for $50.6 \%$ of the stroke patients. The most common stroke mimic was cerebral atrophy, seen in 6 patients, and followed by IC tumours (including astrocytoma and meningioma) as shown in Table 5. The stroke mimics were commonly seen in female patients than male patients, however, the relationship was not statistically significant $(p=4.23)$

Table 1: The Age and Sex Distribution of the Study Population

\begin{tabular}{cccc}
\hline Age Group (years) & Male (\%) & Female (\%) & Total (\%) \\
$1-10$ & $2(1.2)$ & $1(0.7)$ & $3(2.2)$ \\
$11-20$ & $4(2.9)$ & $0(0.0)$ & $4(2.9)$ \\
$21-30$ & $4(2.9)$ & $4(2.9)$ & $8(5.8)$ \\
$31-40$ & $10(7.2)$ & $7(5.1)$ & $17(12.3)$ \\
$41-50$ & $20(14.5)$ & $13(9.4)$ & $33(23.9)$ \\
$51-60$ & $21(15.2)$ & $14(10.1)$ & $35(25.4)$ \\
$61-70$ & $15(10.9)$ & $8(5.8)$ & $23(16.7)$ \\
$71-80$ & $3(2.2)$ & $7(5.1)$ & $10(7.2)$ \\
$81-90$ & $4(2.9)$ & $1(0.7)$ & $5(3.6)$ \\
Total & $\mathbf{8 3 ( 6 0 . 1 )}$ & $55(39.9)$ & $\mathbf{1 3 8 ( 1 0 0 )}$ \\
\hline
\end{tabular}

Table 2: CT Findings of the Study Population

\begin{tabular}{|c|c|c|c|}
\hline \multicolumn{4}{|c|}{ Sex Frequency } \\
\hline CT Finding & Male (\%) & Female $(\%)$ & Total (\%) \\
\hline Normal & $20(14.5)$ & $12(8.7)$ & $32(23.2)$ \\
\hline Stroke & $55(39.9)$ & $33(23.9)$ & $88(63.8)$ \\
\hline Stroke Mimic & $8(5.8)$ & $10(7.2)$ & $18(13.0)$ \\
\hline Total & $83(60.1)$ & 55 (39.9) & $138(100)$ \\
\hline
\end{tabular}

Table 3: Distribution of Stroke Subtypes with Sex

\begin{tabular}{llcc}
\hline & \multicolumn{2}{c}{ Sex Frequency } & \\
Stroke Subtype & Male (\%) & Female (\%) & Total (\%) \\
Brain Infarction & $36(65)$ & $20(61)$ & $56(64)$ \\
Intracerebral Haemorrhage & $17(31)$ & $12(36)$ & $29(33)$ \\
Subarachnoid Haemorrhage & $2(4)$ & $1(3)$ & $3(3)$ \\
Total & $\mathbf{5 5 ( 1 0 0 )}$ & $\mathbf{3 3 ( 1 0 0 )}$ & $\mathbf{8 8 ( 1 0 0 )}$ \\
\hline
\end{tabular}


Table 4: Distribution of Stroke Sides with Sex

\begin{tabular}{lccc}
\hline & \multicolumn{2}{c}{ Sex Frequency } & \\
Stroke Side & Male (\%) & Female (\%) & Total (\%) \\
Left Hemisphere & $26(49.1)$ & $17(53.1)$ & $43(50.6)$ \\
Right Hemisphere & $21(39.6)$ & $14(43.8)$ & $35(41.2)$ \\
Bilateral & $6(11.3)$ & $1(3.1)$ & $7(8.2)$ \\
Total & $\mathbf{5 3 ( 1 0 0 )}$ & $\mathbf{3 2 ( 1 0 0 )}$ & $\mathbf{8 5 ( 1 0 0 )}$ \\
\hline
\end{tabular}

Table 5: Distribution of Stroke Mimics with Sex

\begin{tabular}{lccc}
\hline & \multicolumn{2}{c}{ Sex Frequency } & \\
Stroke Mimic & Male (\%) & Female (\%) & Total (\%) \\
Intracranial Tumour & $3(37.5)$ & $1(10.0)$ & $4(22.2)$ \\
Subdural Haemorrhage & $1(12.5)$ & $1(10.0)$ & $2(11.2)$ \\
Infection & & & \\
$\quad$ Intracerebral Abscess & $1(12.5)$ & $2(20.0)$ & $3(16.6)$ \\
$\quad$ Cerebritis & $0(0.0)$ & $1(10.0)$ & $1(5.6)$ \\
$\quad$ Toxoplasmosis & $0(0.0)$ & $1(10.0)$ & $1(5.6)$ \\
Arteriovenous Malformation & $1(12.5)$ & $0(0.0)$ & $1(5.6)$ \\
Cerebral Atrophy & $2(25.0)$ & $4(40.0)$ & $6(33.3)$ \\
Total & $\mathbf{8 ( 1 0 0 )}$ & $\mathbf{1 0 ( 1 0 0 )}$ & $\mathbf{1 8 ( 1 0 0 )}$ \\
\hline
\end{tabular}

\section{DISCUSSION}

Stroke is a major neurological condition worldwide with high morbidity and mortality and its trend increases in developing countries recently. Computed tomography plays a vital role in confirming the diagnosis, differentiating stroke subtypes and ruling out stroke mimics. The management of stroke depends on its subtype. The mean age in the index study was 52 years and the majority were within in the $5^{\text {th }}$ and $6^{\text {th }}$ decades of their lives, which agreed with most studies ${ }^{7,8,10,21,23-25}$ while, some authors reported mean age in $7^{\text {th }}$ decade in their studies. ${ }^{11,13,26,29}$ While, Yunusa et $a l^{18}$ reported $5^{\text {th }}$ decade in their study. In this study, there was male preponderance accounting for $60 \%$ of the study population giving the male to female ratio of 1.5:1. This is in agreement with most studies in Nigeria, ${ }^{71,1,11,18,21,24,28}$ other sub-Saharan African countries, ${ }^{16,33}$ and some Asian countries. ${ }^{27,30-32}$ Male sex is a known non-modifiable risk factor of stroke which explain these findings. However, few authors reported the female preponderance in their studies in North-central Nigeria, ${ }^{34}$ and South Africa. ${ }^{29}$

The index study showed that the accuracy rate of clinically diagnosed stroke as confirmed by brain CT scan of $64 \%$. This is in agreement with previous studies where accuracy rate was reported ranging from $75-84 \%$ of in Northern ${ }^{8}$ and Southern ${ }^{5,20-26}$ Nigeria. A lower rate of stroke (less than $60 \%$ ) was reported by few authors in South-western Nigeria ${ }^{26}$ and Pakistan ${ }^{27}$ and this differed from our finding. The remaining $36 \%$ of the patients had no CT findings of stroke which were either stroke mimics (differentials) or normal findings. These emphasized the importance of brain CT scan in the management of stroke patients and buttress the low accuracy rate of clinical diagnosis of stroke and stroke scores in differentiating its subtypes. Also, $\mathrm{SAH}$ was not considered as a stroke subtype in Hospital stroke scores.

In stroke patients confirmed with CT scan in index the study, 15\% were young people (range 18-40 years). Almost similar finding was reported in a study in south-eastern Nigeria. ${ }^{25}$ This is also similar to the finding of Hamad $e t a l^{32}$ in Qatar. However, Alkali et $\mathrm{al}^{7}$ reported $41 \%$ of young stroke patients in their study conducted in Abuja, Nigeria which disagreed with our findings. The index study showed that $5 \%$ of stroke patients were found in the paediatric age group and they were sickle cell disease patients and this is in concordance with a previous study done in North-western Nigeria ${ }^{18}$ which also showed sickle cell disease as the major risk factor of stroke in children. 
Twenty-three percent of the patients had normal CT finding in this study which disagreed with previous studies in Nigeria with low values (range from 3.3\% to $16 \%){ }^{20,21,23-26,28}$ Normal finding of the clinically suspected stroke patients does not rule out early BI which has subtle changes and also small lacunar infarcts and brainstem lesions might be seen as normal. Therefore, MRI is recommended in early stage of stroke in patients with normal CT finding ${ }^{3,21}$ In our study, $64 \%$ of the patients had BI which was the most common stroke subtype. This agreed with most studies done in Northern Nigeria ${ }^{78,18}$ and Southern Nigeria, ${ }^{14,20,22-24}$ other sub-Saharan African countries, ${ }^{16,29}$ as well as some Asian countries. ${ }^{27,30-32}$ However, BI was reported to be low (around 55\%) of all stroke subtypes in few studies, ${ }^{9,21,25}$ and reported as low as $40 \%$ in a study in Tanzania, subSaharan Africa. ${ }^{33}$ A high value of about $80 \%$ of BI was reported by few authors in Nigeria ${ }^{5,2}$ and Qatar, ${ }^{32}$ which is similar to findings reported in many developed countries ${ }^{4,5}$ but these findings differed with our finding.

In this study, ICH accounted for 33\% of the cases. Many authors also reported similar findings on $\mathrm{ICH}$ in Nigeria, ${ }^{7,8,18,20,22-25,34}$ other sub-Saharan African countries $^{16,29}$ and some Asian countries. ${ }^{27,31}$ While, some researchers reported findings (range 44-46\%) that were higher than our finding in Nigeria. ${ }^{9,21}$ In some studies in Nigeria ${ }^{5}$ and $\mathrm{Asia}^{30,32}$ reported ICH accounted for about $20 \%$ of stroke cases, which is similar to what is obtained in developed countries. ${ }^{4}$ However, Matuja and co-workers reported that the majority (54\%) of stroke cases were ICH in a study in Tanzania.

Subarachnoid haemorrhage was reported in 3\% of the stroke patients in our study which agreed with previous studies in Nigeria ${ }^{7,34}$ and other developing countries $^{30,31}$ but disagreed with some investigators who reported low values. ${ }^{18,32}$ It is a subtype of stroke, but some authors did not consider SAH in their respective studies. ${ }^{8,9,16,21,22,24,27-29}$ Onwuekwe et $a l^{25}$ recorded as high as $16 \%$ of SAH cases in their studies in South-eastern Nigeria. Also, a study in North-central Nigeria reported $17 \%$ of SAH but it was in young adult patients. ${ }^{19}$ These observations disagreed with our finding. Males predominate in all stroke subtypes in the present study, and this agreed with many authors, ${ }^{5,16,21,24,28,30}$ while Taiwo et $a l^{34}$ reported females dominance in BI in their study but Bello et $\mathrm{al}^{20}$ reported no gender difference.
The left cerebral hemisphere was the most common site involved in this study; this is similar to the previous studies in Southern Nigeria. ${ }^{5,21}$ This might be because the left hemisphere is the dominant side in most individuals. However, Taiwo et $a l^{34}$ in North-central, Nigeria reported that stroke commonly involved the right hemisphere.

The index study showed that $13 \%$ of the patients had stroke mimics and they were mostly females with cerebral atrophy being the most common stroke mimic, followed by IC tumours. This was in concordance with previous authors who reported a frequency of $9-23 \%$ in Nigeria ${ }^{20,21,23,25}$ and Pakistan. ${ }^{27}$ However, Eze et $\mathrm{l}^{24}$ recorded a low frequency of $6 \%$, while Lutsi et $a l^{28}$ and Ogun $e t a l^{26}$ reported higher values of $26 \%$ and $27 \%$ respectively in their studies, which differed from our finding. These showed the important role of $\mathrm{CT}$ scan in confirming the diagnosis of stroke and ruling out stroke mimics (differentials). Previous investigators also reported that the most common stroke mimic was cerebral atrophy in their respective studies, ${ }^{21,26,28}$ while some authors ${ }^{24,25}$ reported that the intracranial tumours were the commonest stroke mimic in their studies.

The limitations of the study were: it was a retrospective study, like most retrospective studies; clinical information was scanty which might affect the exclusion criteria like the history of recurrent stroke and stroke dating more than 15 days. Due to technical factors, the scanner was faulty within few weeks of the study period. Some suspected stroke patients could not do CT scan because of financial constraint during the study period. Some patients from surrounding villages could not travel to do CT scan at Maiduguri because of 'Boko haram' insurgency (insecurity) during the study period. Ignorance of some patients especially those living in rural areas might affect the patients turn out. All these factors might have affected the results of this study.

\section{CONCLUSION}

Stroke is a major cause of high morbidity and mortality worldwide and its trend increases in developing countries including Nigeria. In our study, $64 \%$ of the clinically diagnosed patients were confirmed with CT and the remaining was clinically misdiagnosed stroke. Brain infarction was the most common subtype and its proportion 
was similar to what is obtained in most studies in developing countries. Stroke mimics are strong differentials of stroke and should be ruled out by CT scan. Computed tomography plays a vital role in the management of patients with stroke. Therefore, it is recommended in the evaluation of all stroke patients. Health caregivers, Government and nongovernmental organisations should improve the public awareness of the role of CT scan in stroke management and should also make CT scan not only more available but readily affordable and accessible. Normal (negative) CT findings in clinically suspected stroke patients need further evaluation with MRI.

\section{REFERENCES}

1. Walter J, Oyere O, Mayowa O, Sonal S. Stroke: a global response is needed. Bull World Health Organ 2016; 94: 634-634A. doi: http://dx.doi.org/10.2471/BLT.16.181636. Accessed on 2nd March, 2019.

2. Feigin VL, Norrving B, Mensah GA. Global Burden of Stroke. Circ Res 2017; 120: 439448.

3. Sacco RL, Kasner SE, Broderick JP, Caplan LR, Connors JJ, Culebras A, et al. An updated definition of stroke for the $21^{\text {st }}$ century: A statement for healthcare professionals from the American Heart Association/American Stroke Association. Stroke 2013; 44: 2064-89.

4. Owolabi LF, Nagoda M. Stroke in Developing Countries: Experience at Kano, Northwestern Nigeria. Sudan JMS 2012; 7(1): 9-14.

5. Ikpeme AA, Bassey DE, Oku AO, Ephraim PE. Computerized tomography findings of cerebrovascular disease in adults in Calabar, Nigeria. West Afr J Radiol 2014; 21(1): 12-16.

6. Danesi M, Okubadejo N, Ojini F. Prevalence of stroke in an urban, mixed income community in Lagos, Nigeria. Neuroepidemiology 2007; 28: 216-223.
7. Alkali NH, Bwala SA, Akano AO, Osi-Ogbu O, Alabi P, Ayeni OA. Stroke risk factors, subtypes, and 30-day case fatality in Abuja, Nigeria. Niger Med J 2013; 54:129-35.

8. Salawu F, Umar I, Danburam A. Comparison of two hospital stroke scores with computerized tomography in ascertaining stroke type among Nigerians. Ann Afr Med 2009; 8: 14-18.

9. Nyandaiti YW, Bwala SA. Validation study of the Siriraj stroke score in North-east Nigeria. Nigerian Journal of Clinical Practice 2008;11(3):176-180.

10. Watila MM, Nyandaiti YW, Ibrahim A, Balarabe SA, Gezawa ID, Bakki B, et al. Risk factor profile among black stroke patients in Northeastern Nigeria. Journal of Neuroscience and Behavioural Health 2012; 4(5): 50-58.

11. Owolabi LF, Nagoda M. Stroke in Developing Countries: Experience at Kano, Northwestern Nigeria. Sudan JMS. 2012; 7(1): 9-14.

12. Owolabi LF, Ibrahim A. Stroke in Young Adults: A Prospective Study from Northwestern Nigeria. ISRN Neurology 2012 ; Article I D 468706 . doi:10.5402/2012/468706.

13. Komolafe MA, Komolafe EO, Fatoye F, Adetiloye V, Asaleye C, Famurewa O, et al. Profile of stroke in Nigerians: A prospective study. Afr J of Neuro Sci 2007; 26: 6-13.

14. Chukwuonye II, Ohagwu KA, Uche EO, Chuku A, Nwanke RI, Ohagwu CC, et al. Validation of Siriraj Stroke Score in Southeast Nigeria. International Journal of General Medicine 2015; 8:349-353.

15. Sarfo FS, Akassi J, Awuah D, Adamu S, Nkyi C, Owolabi M, Ovbiagele B. Trends in stroke admission and mortality rates from 1983 to 2013 in central Ghana. Journal of the Neurological Sciences 2015;357(1):240-245.

16. Sagui E, M'Baye PS, Dubecq C, Fall KB, Niang A, Gning S, et al. Ischemic and 
Haemorrhagic Strokes in Dakar, Senegal: A Hospital-Based Study. Stroke 2005;36: 18441847.

17. Walker RW, Jusabani A, Aris E, Gray WK, Mitra D, Swai M. A prospective study of stroke sub-type from within an incident population in Tanzania. S Afr Med J 2011; 101:338-344.

18. Yunusa GH, Saidu SA, Ma'aji SM, Danfulani M. Pattern of computerized tomography of the brain findings in stroke patients in Sokoto, Northwestern Nigeria. Ann Afr Med 2014;13: 217-20.

19. Oyinloye $\mathrm{O}$, Nzeh D, Adesiyun O, Ibrahim $\mathrm{M}$, Akande H, Sanya E, et al. Neuroimaging of young adults with stroke in Ilorin Nigeria. Ann Afr Med 2015; 14: 82-8.

20. Bello TO, Aremu AA, Mustapha AF, Olugbenga-Bello AI. Cranial computerised tomographic assessment of cerebrovascular disease in Osogbo, Nigeria. West Afr J Med 2010;29:323-6.

21. Ogunseyinde AO, Atalabi OM. Cranial computerized tomography in the evaluation of stroke in Ibadan. Niger J Clin Pract 2003; 6: 81-3.

22. Ogbole GI, Owolabi MO, Ogun O, Ogunseyinde OA, Ogunniyi A. Time of presentation of stroke patients for CT imaging in A Nigerian tertiary hospital. Ann Ibd. Pg. Med. 2015; 13(1): 23-28.

23. Onubiyi CCB, Nwankwo NC, Onwuchekwa RC, Ray-Offor OD, Eweputanna LI. Computerized tomography and clinical correlation of stroke diagnosis in University of Port Harcourt Teaching Hospital. Journal of Medicine and Medical Sciences 2015; 6(5): 90-94.

24. Eze CU, Okaro AO, Ohagwu CC. Pattern of computed tomography findings in cerebrovascular accident patients in south eastern Nigeria - a retrospective study of
480 patients. Eur J Sci Res 2009;34: 104-109.

25. Onwuekwe IK, Ezeala-Adikaibe BA, Ohaegbulam SC, Chikani MC, Amuta J, Uloh HN. Stroke mimics - A study of CT images in Nigerian African stroke patients. Journal of Neurological Sciences [Turkish] 2008;25(3);148-154.

26. Ogun SA, OluwoleSO, Oluremi A, Fatade

AO, Ojini F, Odusote KA. Accuracy of the Siriraj stroke score in differentiating cerebral haemorrhage and infarction in African Nigerians. Afr J Neurol Sci 2001; 20: 21-6.

27. Khan J, Rehman A. Comparison of clinical diagnosis and computerized tomography in ascertaining type of stroke. J Ayub Med Coll Abbottabad. 2005; 17: 65-67.

28. Luntsi G, Pindiga BY, Ahmadu MS, Nwobi IC, Eze CU, Aminu UU, et al. Evaluation of Pattern of Lesions Depicted on Brain Computed Tomography of Patients Presenting with Stroke in a Tertiary Hospital in Northern Nigeria. International Journal of Advanced Research 2015; 3(5): 1216-1222.

29. Daffue K, Joubert G, Otto S. Computed tomography stroke findings and population demographics at Pelonomi Hospital, Bloemfontein. S Afr J Rad 2016; $20(1), \quad$ a 993. http://dx.doi.org/10.4102/ sajr.v20i1.993.

30. Al-Rajeh S, Awada A, Niazi G, Larbi E. Stroke in a Saudi Arabian National Guard Community: Analysis of 500 Consecutive Cases From a Population-Based Hospital. Stroke1993; 24(11):1635-1639.

31. Chhetri PK, Raut S. Computed tomography scan in the evaluation of patients with stroke. Journal of College of Medical Sciences-Nepal. 2012;8(2):24-31.

32. Hamad A, Hamad A, Sokrab TEO, Momeni S, Mesraoua B, Lingren A. Stroke in Qatar: A one-year, hospital-based study. Journal of 
Stroke and Cerebrovascular Diseases 2001; 10(5): 236-241.

33. Matuja W, Janabi M, Kazema R, Mashuke D. Stroke subtypes in black Tanzanians: a retrospective study of computerised tomography scan diagnosed at Muhimbili National Hospital, Dar es Salaam. Trop Doc 2004;34:144-6.
34. Taiwo YF, Igoh EO, Ani CC, Pam SD, Yakubu K, Taiwo FO. Acute stroke in Jos University Teaching Hospital: Cranial computed tomographic findings and accuracy of the clinical diagnosis. Sahel Med J 2019; 22: 71-6.

Cite this article as: Umar UH, Yunusa DM, Farate A, Ahmadu MS, Umar UA, Ali AM. Brain Computed Tomographic Findings of Stroke Patients in Maiduguri, North-Eastern Nigeria. KJMS 2021; 15(1): 45 - 53. 